\title{
A Cross-Sectional Study of Students' Learning Progression in Algebra
}

\author{
Edelyn A. Cadorna ${ }^{1, *}$, Erwin F. Cadorna ${ }^{2}$, Joseph G. Taban ${ }^{3}$ \\ ${ }^{1}$ University Research and Development Office, University of Northern Philippines, Vigan City, Philippines \\ ${ }^{2}$ College of Teacher Education Graduate Studies, University of Northern Philippines, Vigan City, Philippines \\ ${ }^{3}$ College of Arts and Sciences, University of Northern Philippines, Vigan City, Philippines
}

Received December 13, 2020; Revised January 15, 2021; Accepted February 24, 2021

\section{Cite This Paper in the following Citation Styles}

(a): [1] Edelyn A. Cadorna, Erwin F. Cadorna, Joseph G. Taban, "A Cross-Sectional Study of Students' Learning Progression in Algebra," Universal Journal of Educational Research, Vol. 9, No. 3, pp. 449-460, 2021. DOI: 10.13189/ujer.2021.090304.

(b): Edelyn A. Cadorna, Erwin F. Cadorna, Joseph G. Taban (2021). A Cross-Sectional Study of Students' Learning
Progression in Algebra. Universal Journal of Educational Research, 9(3), 449-460. DOI: 10.13189/ujer.2021.090304.

Copyright $\bigcirc 2021$ by authors, all rights reserved. Authors agree that this article remains permanently open access under the terms of the Creative Commons Attribution License 4.0 International License

\begin{abstract}
This study explored the learning progression in Algebra of students from a cohort perspective and individual perspective. Utilizing the cross-sectional and longitudinal research methods and employing the Rasch measurement modeling, the progress in the Algebraic performance of the 592 students (Grade 8, Grade 9 and Grade 10) in a school division in the Philippines was examined four times in around one academic year. Analyses revealed that the students only have a low level of performance in Algebra. Through the Rasch analysis, there was a progress in students' Algebraic performance from a cross-sectional perspective. Their ability estimates increased with the grade level. The performance of the students also developed from the individuals' perspective. More students displayed progress while some retrogressed in their performance in the algebraic test. Moreover, from an individual perspective, the algebraic students' performance developed over the period in all grade levels. There is also an increase in the mastery of the students in the different tasks in the test. The answers of the students are dependent on their ability, as predicted from the Rasch model.
\end{abstract}

Keywords Algebra, Cross-Sectional, Learning Progression, Rasch Analysis

\section{Introduction}

Algebra is one of the domains in mathematics for students in junior high school and is also being introduced at the elementary level, as indicated in the K-12 mathematics curriculum. It plays a fundamental role in understanding and appreciating key concepts and principles applied using appropriate technology in problem-solving, communicating, reasoning, and making connections, representations, and decisions in real life. It includes algebraic notations and symbols, equations, and, most importantly, functions to represent and analyze relationships.

This domain is crucial in obtaining the concepts of other domains such as Statistics, Probability, and Calculus. It is requisite in acquiring higher-order thinking skills, as one of the thinking skills needed in the $21^{\text {st }}$ century that can make students more critical, creative, and innovative in solving problems. Students with higher-order thinking skills can distinguish clear ideas, clear opinions, solve problems, formulate explanations, and simplify complicated things. It is applied to solve problems in other fields of science.

Algebra is a very crucial concept in Mathematics. It deals with the study of rules on operations, relations, constructions, including terms, polynomials, equations, and algebraic structures and algebraic properties. Meanwhile, algebraic properties proved to provide an adequate source of many misconceptions among learners. [1] Algebra embodies many of the most important ideas and symbolic conventions in the language of mathematics [2]. Solving a mathematical problem involves understanding the known and unknown information and the relations among factors in the problematic situation. 
Representation of factual and relational information in the compact, unambiguous mathematics language requires applying quantitative reasoning to develop a mathematical model of the problem's conditions. Hence, an effective problem solver is someone proficient in Algebra.

The ideas of Christmas and Fey [2] are supported by the National Council of Teachers of Mathematics (NCTM) [3] as cited by Becker [4] that Algebra is more than a set of procedures for manipulating symbols. It provides ways of exploring, analyzing, and representing mathematical concepts and ideas. It can describe relationships that are purely mathematical or ones that arise in real-world phenomena.

NCTM emphasized that algebraic concepts and skills should be the focus of the K-12 curriculum. Algebra is considered a gateway to STEM professions [5-7]. Moreover, it helps students connect mathematical representations, mathematics topics, and disciplines that rely on mathematical relationships [3].

Concerning the importance of Algebra, the Philippines began implementing the K-12 Curriculum in 2013, including Algebra as a component in most Mathematics subjects. An understanding of Algebra as a course of study and a collection of mathematical aptitude develops over time. Students must encounter algebraic ideas across the K-12 curriculum. Teachers need to help the students at the secondary level improve their competence in making numerical relationships in terms of symbols.

However, teachers complain that some students are not proficient in basic algebraic algorithms and cannot apply them correctly despite the importance of Algebra. They further emphasized that the improvement or progression of students' algebraic proficiency should also be the National Mathematics Advisory Panel's concern. [8]

In the Philippines, there have been many research studies that proved students' low performance in Algebra and other mathematics subjects. Learning Algebra, especially in the early grade levels, has some challenges for students. Many studies have been conducted to identify these challenges or difficulties hindering the appreciation of mathematics and the acquisition of skills the students needed. Students have difficulties in understanding the problem, understanding the meaning of variables, and in basic operation [9]; solving algebraic operation problems [10]; understanding fractions [11]; and rational numbers [12].

Therefore, the researchers see the need to investigate whether there is a progression of students' skills and understanding of algebraic concepts and how they progress in secondary education. In the locality, particularly in Region I, Philippines, there is no attempt to study how the students' learning in any subject develops or progresses. All studies are focused on the mathematics proficiency level of students at a given time. Therefore, the researchers were challenged to study students' learning progression in Algebra in different grade levels.
Considering the importance of Algebra in other mathematics subjects, the study's findings can serve as a basis for school administrators to improve the implementation of the K-12 curriculum, particularly in mathematics. The results may also guide the teachers on possible ways of devising their teaching strategies to make Algebra more challenging and meaningful, which leads to more meaningful learning and eventually to higher students' proficiency level. On the part of the researchers, the study's methodology may inspire them to use advanced statistical analysis like the Rasch model for better analysis and understanding of learning outcomes.

\subsection{Research Objective}

The general objective of this study is to explore the learning progression in Algebra of secondary students. Specifically, it sought to determine the performance level in Algebra of the students across grade level, how their algebraic performance develops from a cross-sectional perspective and an individual perspective in almost one school year.

\section{Literature Review}

\subsection{Learning Progression}

Learning Progression refers to how students learn and develop with increasing sophistication in their knowledge, thus articulating the pathway and conceptual milestones that students need to reach toward achieving the target standards.

According to Shavelson and Kurpius [13], there are three essential elements of learning progression. These include the notion of learning as developmental that happens over time, the importance of instruction in facilitating students' learning as they progress from novice to expert in understanding concepts, and empirical research and validation [14].

Learning progression can be used as a framework for improving the curriculum. It may help curriculum developers understand when and how order and intensity, specific content, and skills should be taught [15]. Students' difficulties can also be associated with specific curricular activities that may help teachers address such difficulties and probing understanding to address students' misconceptions [16].

\subsection{Difficulties in Algebra}

Several authors have studied the difficulties encountered by students in learning algebra. The qualitative study conducted by Sugiarti and Retnawati [10] involving Grade 8 junior high school students in Central Java, Indonesia found the following difficulties: doing 
algebraic problems related to concept and principle, determining variables and constants including but not understanding the definitions of variables and constants, and applying the concept of division in algebra. The students also experienced difficulty using the principle of addition to the algebraic form, the reduction in algebraic form, multiplication on the algebraic form, simplifying algebraic fractions, factoring, and solving algebra-related stories.

The difficulties of Indonesian students in solving the Algebra problem of higher-order thinking skills are caused by the following: 1) difficulty in understanding the information and questions provided, 2) difficulty in finding patterns and relationships, 3) difficulty in manipulating algebraic forms, 4) absence of materials needed, 5) difficulty in solving equations made, and 6) difficulties in manipulating algebraic forms. It was also difficult for the students to present images as symbols or equations and to differentiate two linear equations from linear equations and two linear equations. Students find it very challenging to address issues that require the ability to evaluate because of their difficulties in knowing the problems and questions from the metrics of assessing, evaluating, and making. The student does not establish a hypothesis when the researcher offers a little support. In criticizing and drawing conclusions about a problem, it was also difficult for learners who could make hypotheses. Knowing the challenges of learners, educators, and schools will include learning that can minimize challenges and improve HOTS skills to reach the 21st century. [17]

To explore students' difficulties in solving word problems in algebra, Jupri and Drijvers [18] carried out a teaching experiment involving 51 Indonesian students who used a digital mathematics environment. The perspective of mathematization, i.e., the activity to transform a problem into a symbolic mathematical problem, and to reorganize the mathematical system, was used to identify students' difficulties on the topic of linear equations in one variable. The results show that formulating a mathematical model - evidenced by errors in formulating equations, schemas, or diagrams - is the main difficulty. This highlights the importance of mathematization in the learning and teaching of Algebra.

Based on these results, teachers must develop teaching algebra strategies to minimize students' difficulties in learning algebra. Focus on understanding concepts in Algebra should be emphasized. It is easy to memorize something and even do well on a test without having any real idea about what is going on. As a result, when students have to solve problems that are not the same but similar to the lessons they have learned, they find it hard to obtain the right answer and are challenged with what steps to undertake. Hence, understanding mathematics must be the highest goal. This can be achieved by providing students with varied teaching and learning strategies.

\subsection{Competencies in Algebra}

The algebraic competencies of college students and four cognitive skill levels include knowledge, comprehension, application, and analysis. Findings showed that a sample of students from the Philippines passed only at the comprehension level. Moreover, the students appeared to be weak in all four cognitive skill levels. [19]

Furthermore, in the Philippines, Ramos [20] conducted a study to determine first-year college students' mathematics proficiency. Findings revealed that assisting students while they perform mathematics tasks can improve students' proficiency in the subject. Therefore, it was emphasized in the study that the main hindrance which higher education students face in taking on a course in College Algebra is an under-prepared background in basic mathematics. Hence, the study emphasized the need to do mentoring activities for students who perform poorly in mathematics.

The studies cited delved into determining the level of competence of students in Algebra. However, the students did not explore how the students' learning in the subjects progressed.

\subsection{Rasch Analysis}

Since the study involved students of different grade levels who appear to have varying levels of difficulties and abilities, the Rasch model was used to convert the students' scores to Rasch measures in logits. The Rasch model, a mathematical formula, specifies the person-to-person relationship form of the items that operate one trait. The possibility of higher scores increases as people have more of the trait and decreases as they have less of the trait, making items harder to endorse. The Rasch model assumes that items' response depends on a person's position on the underlying trait and item difficulty. As implicated by the name of the theory, answers to items are modeled instead of total responses. The model does not make allowance for deliberate or unconscious deception, guessing, or any other variable that might affect the answers provided. Researchers model only the trait and not minor, peripheral influences. [21]

The Rasch model is a one-parameter model. It models the difference of "one" parameter between the position of the person and item difficulty. However, it provides two estimates of parameters: person position and the item difficulty, often referred to as logit of the person and logit of the item, respectively, where a logit is a translation of the raw score. [21] The Rasch Analysis constructs equal interval measures where persons and items exist on a standard scale. In other words, raw scores nonlinearly transform into position estimates for items and persons so that the data best fit the model. 


\section{Methodology}

\subsection{Research Design}

The study used a combination of cross-sectional and longitudinal research designs. It employed the cross-sectional research design to compare the algebraic development of students' different cohorts (Grade 8, Grade 9, and Grade 10). Meanwhile, the study used a longitudinal design to determine students' learning progression in almost one school year by looking into the proficiency of the students in Algebra four times during the school year.

\subsection{Participants}

Study participants were the students from two sections of Grades 8, 9, and 10 in three big national high schools in Ilocos Sur, Philippines. These two sections of students were one from the special science classes and one from the regular classes in each of the schools. A total of 778 students participated in the study, who took the assessment at least once. However, only those who completed the first up to the fourth assessment (592) were analyzed. This includes 198 Grade 10, 201 Grade 9, and 193 Grade 8 students.

\subsection{Instrument}

The study used four 10-item tests in Algebra, a total of 40 items, to measure the students' learning progression. The tests focused on algebraic skills taught in the lower secondary levels (Grade 7-9) and based on the learning competencies in Mathematics formulated by the Department of Education under the K-12 curriculum. The test items cover topics in Algebra, including expanding brackets, simplifying expressions, distribution, solving linear equations, factorization, solving rational equations, evaluating algebraic expressions, determining the value of $\mathrm{x}$ making rational expressions undefined, derivation of formula, and solving radical equations. The test items underwent content validity by three DepEd mathematics teachers for their comments and suggestions. The instrument was also pilot tested to Grade 8-10 students of Lussoc National High School for reliability testing, which yielded a reliability index of 0.75 . In the work of de Vellis [22] as cited in the study of Fulmer, Liang and Lin [23], scale reliability of $0.65-0.70$ is 'minimally acceptable;' and between 0.70 and 0.85 is 'respectable' if the instruments are for research purposes.

\subsection{Ethical Consideration}

Before administering the assessments, the researchers requested permission from concerned authorities, the Superintendents of the two school divisions, the schools' principals, and the teachers handling the students' classes. Since the participants of the study were minor, aged 18 years and below, the researchers distributed Participant Information Sheets to inform them about the purposes and importance of the study. To ensure the participants' privacy and confidentiality, the researchers used code numbers both for hard and soft/electronic copies. The data were only accessed with a password. The participants' responsibilities as participants and their rights to withdraw from the study anytime were discussed. A complete and duly approved Assent Form confirmed their participation.

\subsection{Data Gathering Procedure}

After considering ethical considerations, the four sets of the test were administered to the four cohorts of students four times during the first month of the four quarters. The students were given a series of similar tests in August, November, January, and March of the following year.

\subsection{Data Analysis}

This study used the Rasch model, a one-parameter response item model, to analyze the test results. The Rasch Analysis creates one linear model on which items and persons are located according to their difficulty and ability measures. [24] The Rasch analysis converts the test scores to Rasch measures in logits using the Box \& Fox Analysis and Winsteps [25]. The data gathered were also analyzed using the descriptive and inferential analyses through the Statistical Package for the Social Sciences (SPSS).

\section{Results}

\subsection{The Performance Level of the Students in Algebra}

The students from Grade 8 to Grade 9 students obtained a mean score of 22.13 or $55.33 \%$. There were $11 \%$ (around 65 students) who achieved the "developing" level of proficiency or even higher for all the students. The percentage of students who reached the development level ranged from 8.3 percent to 15.70 percent for the students in the three grades. This claim is evident from the students' highest scores (34-36), which is around 85 to 90 percent. 
Table 1. Scores and Performance Level of the Students

\begin{tabular}{ccccc}
\hline Statistics & Grade 8 & Grade 9 & Grade 10 & Combined \\
\hline $\begin{array}{c}\text { Mean } \\
\text { (\% score) }\end{array}$ & $\begin{array}{c}(49.61 \\
\text { Level }\end{array}$ & $\begin{array}{c}23.86 \\
(59.65 \%)\end{array}$ & $\begin{array}{c}22.82 \\
(57.05 \%)\end{array}$ & $\begin{array}{c}22.13 \\
(55.33 \%)\end{array}$ \\
Min & 6.00 & 10.00 & 7.00 & 6.00 \\
Max & 36.00 & 34.00 & 34.00 & 36.00 \\
Skewness & 0.27 & -0.59 & -0.32 & -0.30 \\
\hline
\end{tabular}

The negative value of skewness also reveals a negatively skewed score distribution. This value indicates that more students obtained scores higher than the computed mean score than those who scored lower than the mean. This is evident in the score distribution for Grade 9 and Grade 10 students. The students in Grade 8 had a positively skewed score distribution. This distribution indicates that more students scored low relative to the mean score.

\subsection{Learning Progression in Algebra of the Students from a Cross-Sectional Perspective}

This section focuses on how the students' performance in Algebra progresses from a cross-sectional perspective, i.e., from Grade 8 to Grade 10. Since the three cohorts of students belong to groups with varying ability levels, the students' learning progression was not compared with high objectivity using their scores in the test. The students in the higher grade have a higher probability of being more skilled in answering the test items compared to Grade 9 and Grade 8 . So, instead of examining the scores of the students, the study used the Rasch scores, which employs one linear scale for all cohorts of students. The Rasch model is a process of estimating both item difficulty and student abilities for a test. [25]. The Rasch model could be estimated for items coded dichotomously, and in rating scales [23]. This study employed dichotomous coding for the answers of the students in the Algebra Test. Hence, the use of the Rasch model to analyze the data is valid. The answers of the students were then converted to ability estimates using the Rasch measurement model.
The Rasch measurement modeling produces the percentile of Rasch measures in logits of the three cohorts of students in the four assessments. These logit scores are displayed in a box and whisker plot. (Please refer to Figure 1). The bar length characterizes the difference in the ability between the best-performing student and the worst-performing student in the group. The thick bar within represents the $25^{\text {th }}$ percentile (P25) in the left end, and the $75^{\text {th }}$ percentile (P75) in the right end. The small black line within the thick bar represents the $50^{\text {th }}$ percentile (P50) of the score distribution. The figure shows the location and the differences in the students' abilities in the three cohorts of students. The percentiles increase with the grade level.

During the first test administration, the median $\left(50^{\text {th }}\right.$ percentile) reveals that the students in Grade 8 (the location of the black line within the thick bar) had ability estimates of -1.14 logits. This logit score is lower than the ability estimates of $50 \%$ of the students in Grade 9 , which is -0.85 . On the other hand, the students in Grade 10 got the highest ability estimates (-0.08).

Looking at the middle 50 percent of the students in the three groups, Grade 8 got the lowest average during the first assessment, and Grade 9 got the highest during the fourth assessment. These averages differ by 3.35 logits.

An analysis of the difference between the ability estimate of the best scoring student and the worst scoring student in each group showed that the highest value attained is 6.58 logits, and the lowest is 4.02 logits. From a cross-sectional perspective, the differences are more or less the same. The differences between the best and worst scoring students are around 5.26 (8.89) logits, in Grade 8, 5.18 logits in Grade 9, and 5.15 logits in Grade 10 during the first assessment. These values indicate the variability of the scores in the different grade levels.

Based on the middle $50 \%$, there was a progression in students' ability from Grade 8 to Grade 10. Their performance in Algebra has progressed from a cross-sectional perspective between the Grade 8 and Grade 9 cohorts and Grade 8 and Grade 10 cohorts. However, there was no growth in their ability between the cohorts of Grade 9 and Grade 10. 


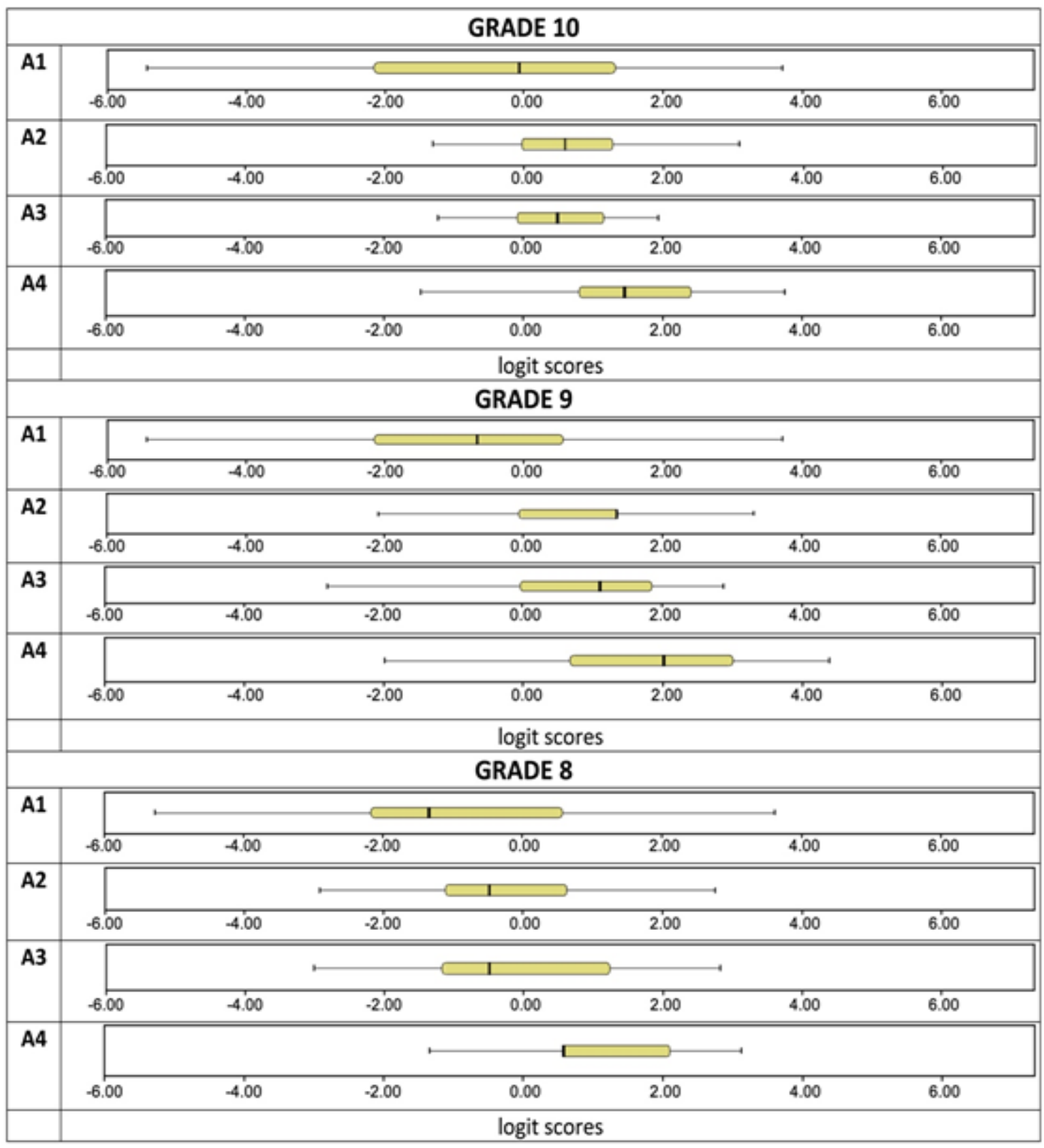

Figure 1. Percentiles of the three cohorts in the four assessments

To examine further how the student's learning progression in Algebra, the study used another measure of average, the mean Rasch estimates in logits. The mean logit scores of students' cohorts in the four assessments were graphed to see the trend. (Please refer to Figure 2). These findings support the findings using the central $50 \%$ of the distribution as a basis.

Table 2. Summary of the Results of One-way ANOVA on the Differences in the Ability Estimate in logits Across Three Cohorts of Students

\begin{tabular}{ccc}
\hline Ability Estimates in the Four Assessments & F & Sig. \\
\hline First Assessment (logit_score Q1) & 9.409 & 0.000 \\
Second Assessment (logit_score Q2) & 21.537 & 0.000 \\
Third Assessment (logit_score Q3) & 21.579 & 0.000 \\
Fourth Assessment (logit_score Q4) & 7.273 & 0.001 \\
\hline
\end{tabular}

To determine whether there are significant differences in the ability estimates among the three cohorts of students, the Rasch scores were analyzed through the One-way Analysis of Variance. Table 2 presents the results of the analysis.

The table reveals that there were significant differences in the mean Rasch measures in logits among the three cohorts of students (F-sig < 0.05). The result implies that the students' algebraic performance across the three groups of students (Grade 8, Grade 9, Grade 10) differ in the first to the fourth assessments. The study also subjected the Rasch measures to Least Significant Differences (LSD) to determine which grade level lies the significant change or difference.

There is consistently a significant difference in the algebraic ability estimates of the students between Grade 
8 and Grade 9, and between Grade 8 and Grade 10 during the first to the fourth assessments. The ability estimates of the students in Grade 9 and Grade 10 were significantly higher than in Grade 8. The result implies that as the grade increases, their ability in algebra improves. However, the

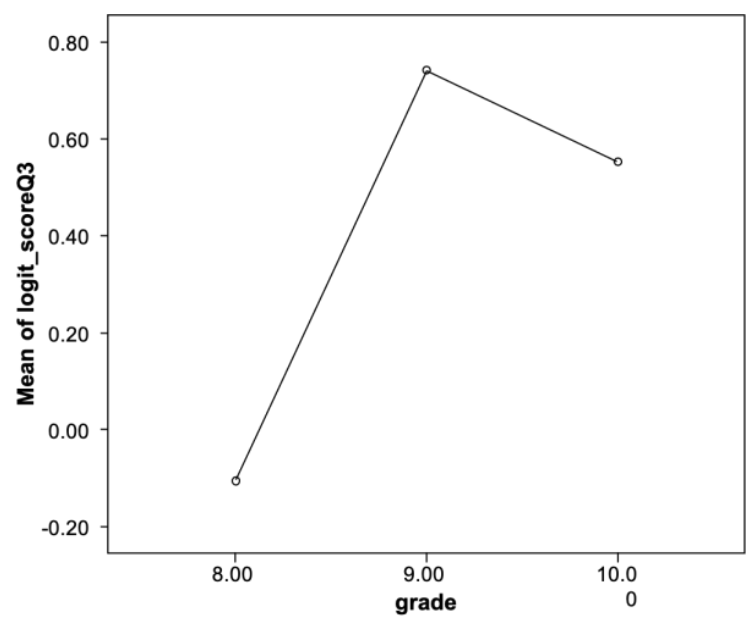

Assessment 1

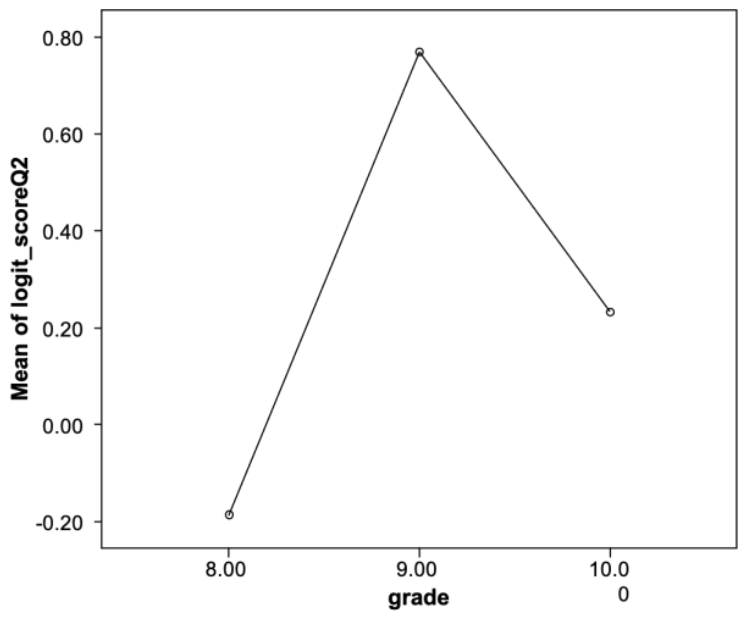

Assessment 3 ability estimates of the students decreased significantly from Grade 9 to Grade 10, but this happened only during the second assessment. During the other assessments, only small improvements were noted and are not statistically significant.

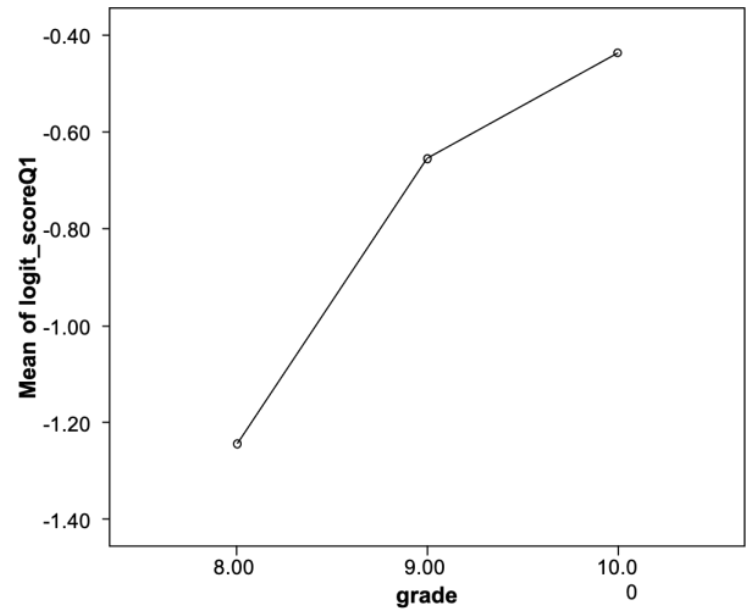

Assessment 2

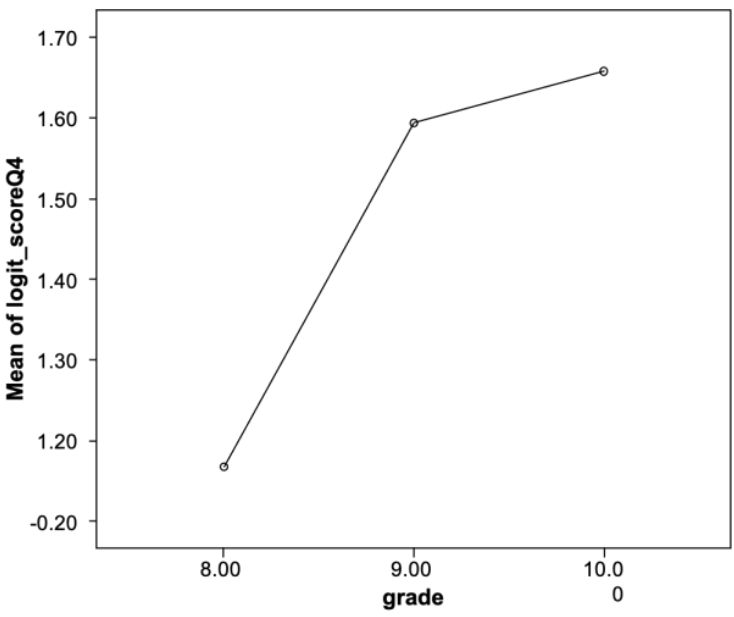

Assessment 4

Figure 2. The trend of mean ability estimates of the students between cohorts of students 


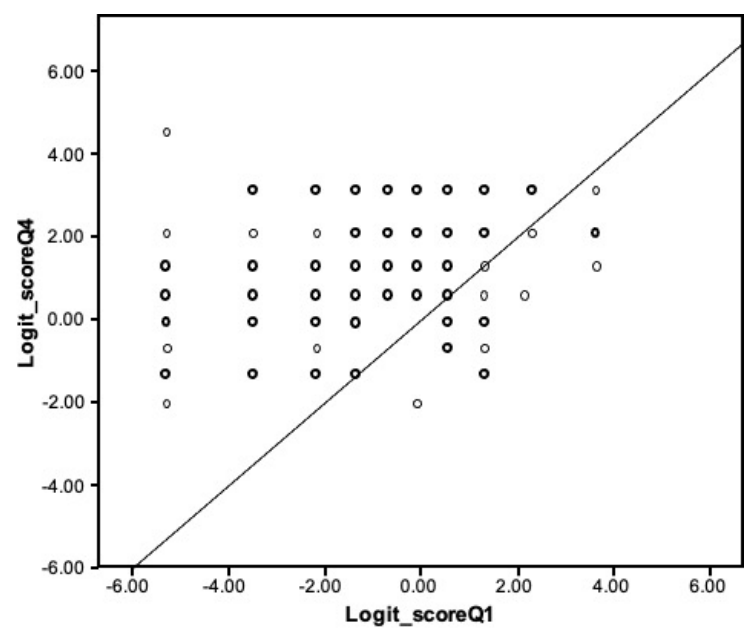

Grade 8

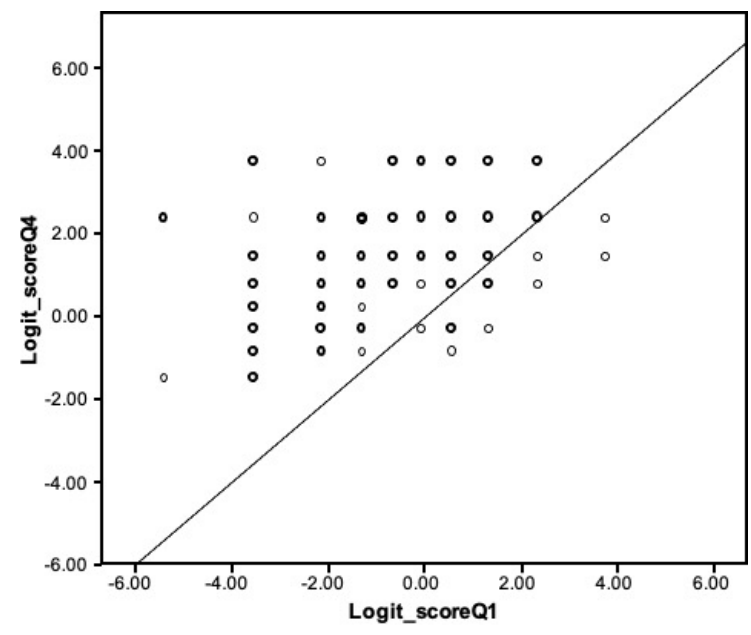

Grade 10

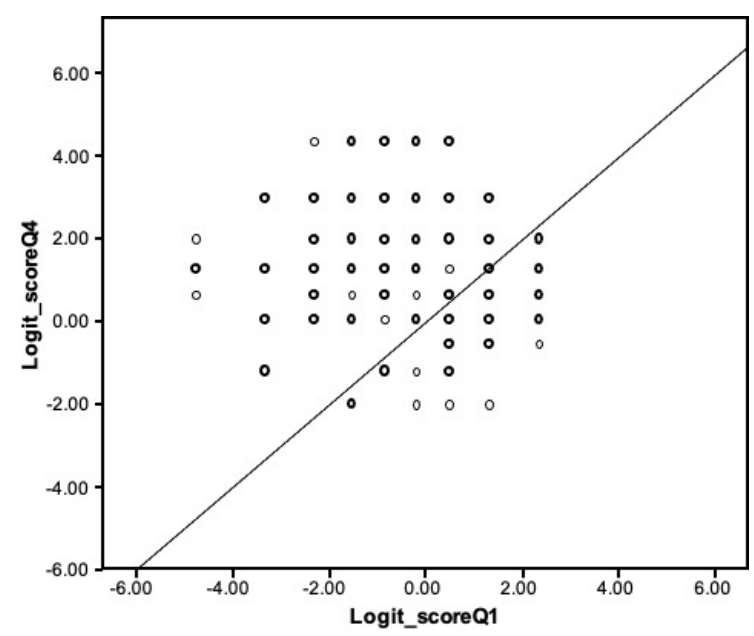

Grade 9

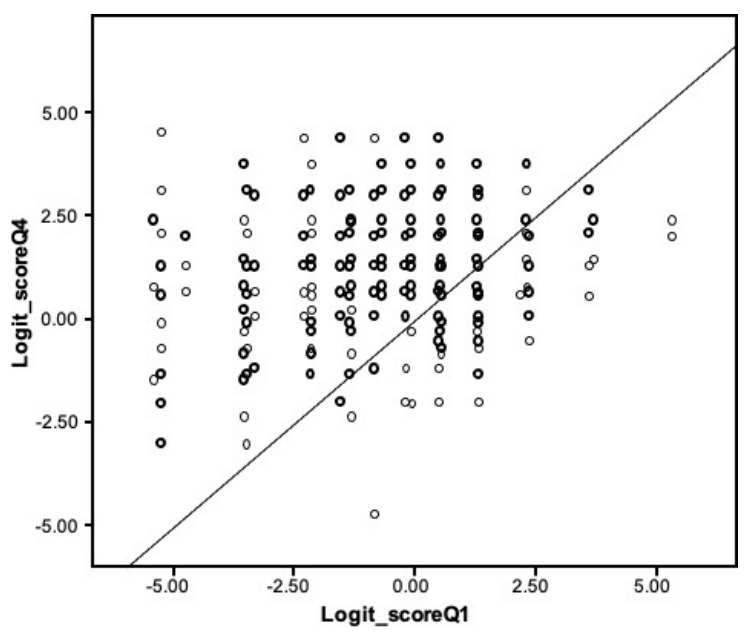

All Students

Figure 3. Students' logit scores in the first assessment versus logit scores in the fourth assessment

\subsection{Development of Students' Algebraic Proficiency from a Longitudinal Perspective}

This section focuses on how the students' learning progression in Algebra from a longitudinal perspective. The study also presents the results of the analysis of the Rasch measures in logits or the ability estimates of the students in Algebra throughout the whole duration of the assessment, from Quarter 1 to Quarter 4.

The study also looked into the students' learning progression based on the number of students who improved their ability from the first to the fourth assessment. Figure 3 displays the graph of the students' ability estimates in Algebra during the first test administration (logit_scoreQ1) versus their ability estimates during the fourth assessment (logit scoreQ4). Each circle in the figure represents an individual student who participated in the first and fourth assessments. The circles above the line represent students with improvement in their performance in the test from the first to the fourth assessments. On the other hand, the circles below the line are those with decreasing performance in the test.

The circles within the line are those that did not change scores in the Algebra Test.

In the figures, there are circles in bold in the four graphs. These are two or more circles that overlapped due to similar scores obtained by the students both in the first and fourth assessments.

As shown by the small circles, there are more circles above the line than those below the line in all Grade levels and when taken as a whole. There were no circles that lie within the line. This finding means that there were more students with increasing ability than those with decreasing ability from the first assessment to the fourth assessment.

In Grade 8, there were many (156 or $80.83 \%$ ) students who showed improvement in their performance in the test during the first and last assessments. The mean improvement in their ability estimates is 2.41 logits. In Grade 9, 161 or 80.10 percent of the students made progress in their algebraic performance while 40 retrogressed. The ability estimates of this group of 
students increased by 2.25 logits. It is in Grade 10 where the greatest percentage of students (166 or 83.84\%) showed progress in their performance and their estimated ability increased by 2.41 logits. Around 82 percent (483) of all the students regardless of grade level showed progress in their scores over around one school year.

To further examine the development of the students, the study determined the number of students who were able to master items in the test for around a school year. From the Rasch model, a probability of $80 \%$ of students answering an item correctly is an expression of mastery of the item. It then follows that a probability of 0.8 of person, $n$, answering item, $i$, correctly corresponds to an ability $\mathrm{B}_{\mathrm{n}}$ which is 1.39 logits higher than the difficulty $\mathrm{D}_{\mathrm{i}}$ of item [8].

Presented in Figure 4 is the number of students who were able to master the items in the test from the first assessment to the fourth assessment.
The table entries reveal that there were already many who mastered the items during the first assessment. As earlier found, these are the least difficult items based on their estimated difficulty. Item 1 measures students' proficiency in doing expansion, particularly in multiplying a monomial expression and binomial expression. Item 2 measures students' proficiency in simplifying algebraic expressions. Meanwhile, item 3 measures proficiency in doing the task on the distribution of terms. The table also shows that nobody was able to master items 8 and 9 . These items were found earlier as the most difficult. Item 8 measures students' competence in rational expression, particularly finding the domain of a function. On the other hand, item 9 measures competence in writing an equation where a variable is a function of another variable.

As further seen from the table, the number of students who were able to master most of the items, except items 8 and 9 , increased over the period.

\begin{tabular}{|c|c|c|c|c|c|}
\hline \multirow{4}{*}{ 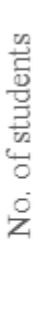 } & \multirow{4}{*}{$\begin{array}{r}700 \\
600 \\
500 \\
400 \\
300 \\
200 \\
100 \\
0\end{array}$} & \multirow{3}{*}{\multicolumn{4}{|c|}{ (2) }} \\
\hline & & & & & \\
\hline & & & & & \\
\hline & & A1 (Aug 2015) & A2 (Nov. 2015) & A3 Jan. 2016) & $\begin{array}{c}\text { A4 (March } \\
\text { 2016) }\end{array}$ \\
\hline & $\mathrm{m} 1$ & 417 & 549 & 578 & 592 \\
\hline & $\mathrm{m} 2$ & 215 & 328 & 342 & 485 \\
\hline & $\mathrm{m} 3$ & 216 & 324 & 344 & 474 \\
\hline & $\mathrm{m} 4$ & 110 & 203 & 248 & 388 \\
\hline & 5 & 113 & 204 & 248 & 419 \\
\hline & $m 6$ & 42 & 73 & 78 & 254 \\
\hline & $\mathrm{m} 7$ & 113 & 204 & 160 & 361 \\
\hline & m 8 & 0 & 0 & 0 & 0 \\
\hline & $\mathrm{m} 9$ & 0 & 0 & 0 & 0 \\
\hline & $\mathrm{m} 10$ & 43 & 112 & 138 & 254 \\
\hline
\end{tabular}

Figure 4. Number of Students who have mastered the items over time 


\section{Discussion}

This study investigated the learning progression in Algebra of three cohorts of students guided by three research objectives. The first sought to determine the students' level of performance in Algebra. Based on the Department of Education's 80\% mastery level, the students' performance is below the mastery level. By grade level, the students' scores in the Algebra test fall within the beginning mastery level. However, the study points out that some students can attain the level of "developing" and even higher. From the key points in mathematics, students who have completed and mastered the content and skills in the lower secondary years will be well-prepared for Algebra in the higher years [26].

The second research objective was to determine how the students' learning in Algebra progresses from a cross-sectional perspective using the students' estimate ability in logits. At the start of the assessment, the students' ability estimate is lowest at the lower grades and highest at the highest grade. The same trend of the data is also true during the second and the third test administrations for Grades 8 and 9. For Grades 9 and 10, however, the middle $50 \%$ of the students' ability estimates are higher in Grade 9 than in Grade 10 during the second, third, and fourth assessments. Using Rasch analysis, the students' mean logit scores reveal an increasing trend in the mean ability estimates of the students from Grade 8 to Grade 10 during the first and fourth assessments. During the second and the third assessments, the mean ability estimate increased from Grade 8 to Grade 9 but decreased from Grade 9 to 10 . The results of ANOVA on the ability estimates imply a significant improvement in the ability estimates of the students from Grade 8 to Grade 9. On the other hand, the improvement from Grade 9 to Grade 10 is not significant. Therefore, there was a development of the proficiency of the students from a cross-sectional perspective.

The students' learning progression in Algebra is very essential information in helping the students define the track they may be or should be on. Learning progressions can inform teachers of what are to be expected from the students. It may provide a basis in making decision regarding the topics to be taught to specific groups of students. The concept of learning progression may help identify key waypoints along the path in which students' knowledge and skills are likely to grow or develop in school subjects [15].

The third research objective was to determine the learning progression in Algebra of the cohorts of students from a longitudinal perspective. The reason why the students' ability estimates in logits during the first quarter were graphed with their ability estimates during the last quarter is to determine who among the students have a significant learning progression from the first to the fourth assessment. There were more students with increasing ability than those with decreasing ability from the first to the fourth assessment. The performance of the students increased by the range logits of $2.25-2.41$, Grade 9 with the least increase and Grade 10, with the highest increase. Therefore, the students showed a learning progression over time from an individual perspective. The results mean that the students were able to develop and demonstrate a more in-depth, broader, more sophisticated, and thorough understanding over time. A learning progression can visually and verbally articulate a hypothesis about how learning will typically move toward increasing understanding for most students [27].

In terms of students' subject mastery relative to the items' difficulty, there is a learning progression in the students' performance in the subject. The study points out that their ability and the difficulty of the items are the basis for determining the students' mastery. Therefore, the ability estimate of the students is higher than the difficulty of the items. However, this is contrary to items 8 and 9 . The absence of students who were able to master items 8 and 9, the most difficult items, implies that the students' ability is lower than the ability required answering these items. It should be pointed out that items 8 and 9 measure students' competencies in making rational expressions undefined, and deriving formula, respectively. The task in item 8 is to find the domain of a function, which is a common difficulty of most students in all grade levels. To enable the students to do the task, they have the basic knowledge of the properties of numbers, that not all numbers can be used to replace a variable in a given rational expression [28]. Meanwhile, item 9 required the students to write an equation of a variable as a function of another variable. The difficulty of the students to carry out this task could be due to their difficulty in manipulating algebraic forms [17].

\section{Conclusions and Recommendations}

The secondary students in the study are at the beginning level of proficiency. However, they made an improvement in their performance in Algebra based on their ability estimates. They were able to master most of the basic algebraic concepts and tasks but not on concepts requiring complicated tasks. The three cohorts of students differ in their algebraic performance. The students' algebraic competence increases with the grade level. However, there is only a minimal difference between the ability of the students in Grade 9 and Grade 10. From a longitudinal perspective, most of the students made an improvement or progress in their performance over around one school year. While it is true that most of the students displayed improvement in their algebraic competence, from both cross-sectional and longitudinal perspectives, some items were too difficult for some students to master.

The aim of teaching mathematics should be to attain a 
higher level of understanding on the part of the students. The teaching of Mathematics, particularly Algebra should focus not only on procedural skills but also on conceptual understanding. The development of conceptual understanding is needed to enable students to solve difficult problems. Also, a study that focuses on students' method or process of solving problems, and an in-depth study on students' development of mathematics proficiency are recommended. Another study that focuses on students' learning concerning structure sense may also be conducted.

\section{Acknowledgments}

The authors are very grateful to the University of Northern Philippines for the research funding, the respondents for answering the series of test items, and to Kriza Rosette Cadorna, for helping in the technical aspect of the manuscript.

\section{REFERENCES}

[1] Mangorsi, S., "Students' conceptions on algebraic properties and their effect on performance in algebra: the case of some public secondary schools in Maguindanao and Lanao del Sur," Advances in Education Sciences, 2014. Retrieved from

http://scinet.dost.gov.ph/union/ShowSearchResult.php?s=2 $\& \mathrm{f}=\& \mathrm{p}=\& \mathrm{x}=\&$ page $=\& \operatorname{sid}=1 \& \mathrm{id}=$ Students $\% 27+$ conception $\mathrm{s}+$ on+algebraic+properties + and + their+effect + on + performa nce + in + algebra \&Mtype $=$ THESES

[2] Christmas, P. T., \& Fey, J. T., "Communicating the importance of algebra to students. In Algebra for everyone, "2007. Retrieved from https://www.learner.org/courses/lear ningmath/algebra /pdfs/AlgebraChapter7_1.pdf

[3] The National Council of Teachers of Mathematics, "Guiding principles for mathematics curriculum and assessment," NCTM, 2009. Retrieved from: https://www.nctm.org/News -and-Calendar/News/NCTM-News-Releases/NCTM-Releas es-Guiding-Principles-for-Math-Curriculum/

[4] Becker, J. P., "Algebra: what, where, and for whom," Southern Illinois University, Dept. of Mathematics \& Instruction. The National Council of Teachers of Mathematics (NCTM), 2008. Retrieved from: http://mathforum.org/kb/servlet/JiveServlet/download/3231868339-6530392-536993/att1.html

[5] National Mathematics Advisory Panel, "Foundations for success. The final report of the National Mathematics Advisory Panel," Washington, DC: U.S. Department of Education, 2008. Retrieved from https://www2.ed.gov/abou $\mathrm{t} /$ bdscomm/list/mathpanel/reports.html.

[6] Siegler, R. S., et al., "Early predictors of high school mathematics achievement," Psychological Science, Vol. 23, No. 7, pp. 691-697, 2012. DOI: 10.1177/095679761244010
[7] Rodrigues, J., Dyson, N., Hansen, N., \& Jordan, N. C., "Preparing for algebra by building fraction science," Teaching Exceptional Children, Vol. 49, No. 2, pp. 134-141, 2017. DOI: $10.1177 / 0040059916674326$.

[8] Stiphout, I. v., Drijvers, P., \& Gravemeijer, K., "The development of students' algebraic proficiency," International Electronic Journal of Mathematics Education, Vol. 8, No. 2, pp. 62-80, 2013. Retrieved from https://www.researchgate.net/publication/289711791_The development_of_students'_algebraic_proficiency.

[9] Pramesti, T. I., \& Retnawati, H., "Difficulties in learning algebra: An analysis of students' errors," Journal of Physics: Conference Series. 1320:012061. Yogyakarta, Indonesia: IOP Publishing Ltd, 2018. DOI: 10.1088/1742-6596/1320/1 /012061.

[10] Sugiarti, L., \& Retnawati, H., "Analysis of students' difficulties in algebra problem-solving in junior high school," Journal of Physics: Conference Series. 1320:012103. Yogyakarta, Indonesia: IOP Publishing Ltd, 2018. DOI: 10.1088/1742-6596/1320/1/012103.

[11] Siegler, R. S., Thompson, C. A., \& Schneider, M., “An integrated theory of whole number and fractions development," Cognitive Psychology, Vol. 62, No. 4, pp. 273-296, 2011. DOI: 10.1016/j.cogpsych.2011.03.001.

[12] Mazzoco, M. M. M., \& Devlin, K. T., "Parts and 'holes' Gaps in rational number sense in children with vs. without a mathematical learning disability," Developmental Science, Vol. 11, No. 5, pp. 681-691, 2008. DOI: 10.1111/j.1467-76 87.2008.00717.x

[13] Shavelson, R. J. \& Kurpius, A., "Reflections on learning progressions," Learning Progressions in Science, pp. 13-26, 2012. Retrieved from http://www.education.msu.edu/projec ts/leaps/proceedings/Shavelson.pdf.

[14] Kobrin, J. L. Larson, S., Cromwell, A. \& Garza, P., “A framework for evaluating learning progressions on features related to their intended uses," Journal of Educational Research and Practice, Vol. 5, No. 1, pp. 58-73, 2015. DOI: 10.5590/JERAP.2015.05.1.04.

[15] Corcoran, T., Mosher, F., \& Rogat, A., "Learning progressions in science: an evidence-based approach to reform," CPRE research report. Consortium for Policy Research in Education, 2009. DOI: 10.12698/cpre.2009.rr6 3 .

[16] Davis, E. A. \& Krajcik, J. S., "Designing educative curriculum materials to promote teacher learning," Educational Researcher, Vol. 34, No. 3, pp. 3-14, 2005. DOI: 0.3102/0013189X034003003

[17] Salsabila, F., Johar, R., \& Bahrun, B., "Students' difficulties in solving higher-order thinking skills problems on algebra content," 8th Annual Conference on Social Sciences. Banda Aceh, Indonesia, 2018. Retrieved from http://www.jurnal.u nsyiah.ac.id/AICS-Social/article/view/12656.

[18] Jupri, A., \& Drijvers, P., "Student difficulties in mathematizing word problems in algebra," EURASIA Journal of Mathematics, Science and Technology Education, Vol. 12, No. 9, pp. 2481-2502, 2016. DOI: eurasia.2016.1299a.

[19] De Mesa, G., Imperio, R., \& Villiamina, J., “Algebra 
competency of first-year college students in Central Bicol State University of Agriculture School Year 2011-2012," 2012. Retrieved from http://www.slideshare.net/080331/alg ebra-competency.

[20] Ramos, M. L., "A basic mathematics proficiency and algebra assistance class for freshman college students," Paper Presented at the ASAIHL Conference. DLSU, 2011. Retrieved from https://silo.tips/download/a-basic-mathemat ics-proficiency-and-algebra-assistance-class-for-freshman-c olleg

[21] Green, K. E., \& Frantom, C. G., "Survey development and validation with the Rasch Model," 2002. Retrieved from https://www.researchgate.net/publication/255658503_SUR VEY DEVELOPMENT AND VALIDATION WITH T HE_RASCH_MODEL.

[22] DeVellis, R., "Scale Development: Theory and Applications (3rd ed.)," Thousand Oaks, CA: Sage Publications, Inc, 2012 .

[23] Fulmer, G. W., Liang, L., \& Liu, X., “Applying a force and motion learning progression over an extended time span using the force concept inventory," International Journal of
Science Education, Vol. 36, No. 17, pp. 1-19, 2014. DOI: 10.1080/09500693.2014.939120.

[24] "The Rasch Model as a construct validation tool," Rasch Measurement Transactions, Vol. 22, No. 1, pp. 1145-1146, 2008. Retrieved from https://www.rasch.org/rmt/rmt221a.ht $\mathrm{m}$.

[25] Bond, T. G., \& Fox, C. M., "Applying the Rasch Model," Fundamental measurement in the human sciences (Second ed.). Mahwah, N.J.: Lawrence Erlbaum, 2007.

[26] Common Core State Standards Initiative, "Key shifts in mathematics," 2010. Retrieved from http://www.corestanda rds.org/other-resources/key-shifts-in-mathematics/

[27] Hess, K., "Using learning progressions to monitor progress across grades: A scientific inquiry learning profile for pre K-4,”Science and Children. Vol. 47, No. 6, pp. 57-61, 2010.

[28] Taban, J \& Cadorna, E., "Structure sense in algebraic expressions and equations of groups of students," Journal of Educational and Human Research Development, Vol. 6, pp. 140-154, 2018. Retrieved from https://www.ijterm.org/inde x.php/jehrd/article/view/89 